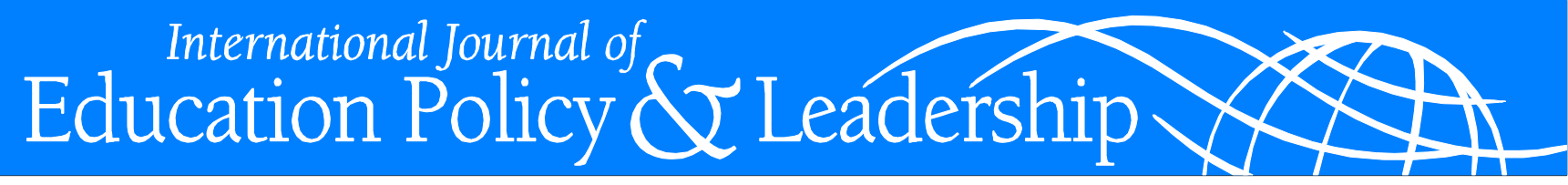

\title{
EducATION FOR A NeW ERA: STAKEHOLdERS' PERCEPTION OF QATARI EDUCATION REFORM
}

\author{
MAHA ELLILI-CHERIF \\ College of Education, Qatar University \\ MICHAEL ROMANOWSKI \\ College of Education, Qatar University
}

\begin{abstract}
The paper reports the results of a qualitative research study that explores principal, teacher, and parent perceptions with regard to Qatar's education reform, Education for a New Era (EFNE) launched in 2004. The study focuses on the effects of the reform on each group, their perceived advantages and disadvantages of the reform, and the challenges they face in the implementation of EFNE. Data for this study was collected through an open-ended questionnaire. The results point to the positive effects of EFNE on improving instruction, principals' leadership style, and learner attitude to education. These stakeholders believe that the reform is too ambitious and sometimes unrealistic. The three groups also report challenges that revolve around the amount of extra effort and work it requires from them, the continuous reform changes, and the threats to the local culture and language. Discussion and conclusions are provided regarding EFNE.
\end{abstract}

Ellili-Cherif, M. \& Romanowski, M. (2013). Education for a New Era: Stakeholders' Perception of Qatari Education Reform. International Journal of Education Policy E Leadership 8(6). Retrieved from www.ijepl.org .

\section{Introduction}

In 2001, Qatar became alarmed that the country's K-12 education system was "not producing high-quality outcomes and was rigid, outdated, and resistant to reform" (Brewer, Augustine, Zellman, Ryan, Goldman, Stasz, \& Constant, 2007, p. iii). Considerations of ways to reform the system prompted the government to commission RAND, a nonprofit research organization, to conduct a far-reaching assessment of the system and provide recommendations for building "a world-class system that would meet the country's changing needs" (Brewer, et al., 2007, p. xvii). The evaluation pointed to a number of problems. First, it revealed that the existing system was highly centralized, with limited strategies for evaluation and monitoring of policies and processes.
Second, it indicated that there was a lack of communication and shared vision among education stakeholders, attributable, in part at least, to a top-down decision-making policy. Finally, it demonstrated that there was an over emphasis on rote learning and little attention to the development of critical thinking.

Upon the completion of its analysis, RAND recommended three options, and the Qatari government elected to support a charter school model that decentralizes education and encourages the development of Independent schools. As a result, RAND initiated a systematic reform plan designed to transform Qatar's schools and Ministry of Education into a world-class competitive education system, known as Education for a New Era (EFNE) (Brewer, et al., 2007). EFNE revolves around four principles: (1) autonomy for schools, (2) 
accountability through a comprehensive assessment system, (3) variety in schooling alternatives, and (4) choice for parents, teachers, and school operators. These principles represent a two-pronged approach to reform that requires the establishment of governmentfunded Independent schools over a multiyear period and the implementation of annual assessments to measure student learning and school performance (Supreme Education Council, 2012a). The first cohort of Independent schools, consisting of 12 schools, opened in 2004. Today, all government-funded schools in Qatar have acquired Independent status.

Together with the introduction of Independent schools, a new body-the Supreme Education Council (SEC)—was established in order to drive education reform and realize the Qatari government vision for the 21st century. The SEC directly supports Independent schools and is essentially responsible for setting curriculum standards and broad goals for the school system, providing professional development for teachers and school leaders, and conducting evaluations of school performance and student progress. In order to ensure a successful implementation of the reform, and mainly to hold schools and student accountable for learning, the SEC plays an integral part in ensuring that teachers are performing according to high standards.

Nine years after the introduction of the reform, Education for a New Era has changed the education landscape. Driven by international curricula and curriculum standards, EFNE has created immense opportunities for international education consulting, with numerous organizations flooding Qatar offering their "expertise" in a variety of education areas. EFNE has raised many questions, but little research has been done on the stakeholders' perceptions of EFNE. In what follows, we examine Qatar's EFNE by presenting the perceptions of principals, teachers, and parents who are directly affected by and involved in the reform. In particular, we are concerned with the challenges, advantages, and disadvantages of the reform and the impact it has on those stakeholders.

\section{Stakeholders and Education Reform}

Education reform is necessary when schools do not achieve the goals of education, as understood by individuals or groups with the power to initiate reform (Horn, 2002). In the case of Qatar, government officials believed there needed to be some changes in the education structure in order for Qatar to meet the country's changing needs as it responds to the forces of globalization. More importantly, directly or indirectly, many stakeholders in education, including students, parents, teachers, administrators, the community as a whole, businesses, and anyone or any group that has an interest in education, are affected by education reform. Fullan and Miles (1992) argue that all large-scale change is implemented locally and the only way that change happens is through the effective daily implementation by principals, teachers, parents, and students. Since they play a crucial role in the implementation of reform, it is important to explore their experiences in the process and obtain their opinions about the change.

The research literature is quite clear that principals play a significant role in successful education reform. The majority of studies on school effectiveness demonstrate that both in the primary and secondary schools, leadership is the key factor in successful reform (Leithwood, Louis, Anderson, \& Wahlstrom, 2004; Sammons, 1999). This is particularly true when schools are facing massive reforms. Matthews and Crow (2003) claim that in every school situation where reform is occurring, the principal is always a significant factor in the efforts to improve schools. Fullan (2001) found that for a reform to be successful it requires support from central administrators and principals. It is the supervision and leadership of principals that motivates staff, parents, and students to deal with and overcome uncertainty and embrace the change process. The majority of education research recognizes that effective schools and school districts that are addressing reform start and end with strong education leadership (e.g., Leithwood, et al., 2004; Kirk \& Jones, 2004; Houston, 1998). 
Principals are the focal point for ensuring that change initiatives do not remain on paper but are implemented within the school. In addition, a principal's leadership not only plays a significant role in education reform but also shapes the school climate regarding how teachers, parents, and students perceive the reform. Therefore, there is a need to examine the effects of reform on principals and investigate ways they can be supported as they strive to implement changes in education.

More important than the role of principals is the role that teachers play in reform implementation (Margolis \& Nagel, 2006; Nunan, 2003; Bailey, 2000; Rea-Dickens \& Germaine 1998; Lieberman, 1997). Teachers are often viewed as change agents, and the success of education reform is determined by their acceptance of, involvement in, and degree of ownership of reform (Carless, 2001; Markee, 1997). Because of their experiences, they understand the realities of communities, schools, and classrooms and can provide a unique perspective that differs from the opinions of decision makers and bureaucrats. One could even argue that teachers have more valuable insight into what will or will not work based on these experiences. Thus, it is important to consider their perspectives when introducing change (Troudi \& Alwan, 2010; Lamie, 2005; Kirk \& Macdonald, 2001).

Education reform demands changes, and these changes ultimately rely on teachers (Lieberman \& Pointer-Mace, 2008; Spillane, 1999; Fullan \& Miles, 1992). In most cases, education reforms are often a top-down process that not only silences teachers' voices but also hampers reform (Hargreaves \& Goodson, 1996). Too often, mandated reforms fail to take into account the input of grassroots educators and do not reflect the importance of educators as professionals capable of making decisions that can benefit the parents and students they serve (Schweisfurth, 2002). Darling-Hammond (1997) points out that when prescriptive policies are created without teacher input, a school's ability to meet the needs of students and parents is greatly reduced. More importantly, teachers are the key to reforms, and leadership that does not include teachers in the process of change is destined to fail (Fullan, 2011; Hargreaves \& Fullan, 1998). Bailey (2000) argues that "teachers' perspectives have been a missing factor in the development of innovations. ... [T] he content and process of change are typically not in the hands of practitioners; change is assumed to be possible without their expertise, and their perspectives on change are frequently ignored" (p. 112). Ignoring teachers' perspectives and input is problematic in that it hampers education reform and creates resistance in some teachers. With that in mind, an argument can be made that teachers are central to education reform, and successful implementation of education change requires teachers to be integrally and meaningfully involved throughout the reform process (Kilgallon, Maloney, \& Lock, 2008; RAND Corporation, 2007; Hargreaves, Earl, Moore, \& Manning, 2001). However, it is not common practice that teachers are included in either the development of reform or the assessment of the implementation.

Similar to the plight of teachers, a common flaw in education reform is that parents are not included in meaningful ways in the reform process, even though they are among the most important stakeholders in any education reform (Adams \& O'Neill, 2010). Christenson and Anderson (2002) stress that student learning is never a product of either schools or families in isolation. In fact, a high level of family involvement is one characteristic of high-performing schools (Henderson \& Mapp, 2002; Lewis \& Anderson, 1997). Parents play a supportive role in the education process and education reform. When reform is implemented, students are directly affected and parents play a vital role in helping their children as they adapt to change. Furthermore, student learning is never a product of either schools or families in isolation (Christenson \& Anderson, 2002). parents can often see the strengths and weaknesses of schools and should be encouraged to offer their perspective (Matthews $\&$ Crow, 2003). In the context of Qatari education, the Supreme Education Council (2008) points out that the key aspect of parental in- 
volvement for children's academic success is the parents' involvement in home-school relationships. The home-school relationship is "the formal and informal connections, communications and partnerships with the child's school and teachers" (Supreme Education Council, 2008, p. 20)—all a valuable part in making education reform successful. Therefore, education policymakers should pay attention to parental involvement and consider parents as a major component of education reform efforts.

\section{Qatari Context: Stakeholders, Princi- pals, and Teachers}

In order to contextualize this study, we will provide some demographics regarding the Independent schools that are examined in this study, the principals and teachers of the Independent school system, and the parents of the students in Independent schools. According to the Supreme Education Council (2012a) "an Independent school is "a government-funded school that is granted autonomy to carry out its educational mission and objectives while being held accountable to terms agreed to in an operating contract." Independent schools are segregated by gender and are broken into primary, preparatory, and secondary schools. The six schools surveyed in this study were from cohort 11 and included two primary female schools with enrollments of 556 and 880, respectively; one primary male school with an enrollment of 625; one male preparatory school with 662 students; one female secondary school with 2165 students; and one male secondary school with an enrollment of 1528.

Each Independent school has an owner or operator and a principal. Depending on the school, the number of assistant principals varies, but each school has a coordinator for the individual departments. There is a wide range of education backgrounds and experi- ences among the principals, but all principals of Independent schools must be Qatari. At the time of this study, all principals receive leadership development programs offered by the Supreme Education Council and can receive ongoing training and support from both the Supreme Education Council and the School Support Organizations (SSO) assigned to each Independent school.

The majority of teachers in Independent schools are expatriates, mostly from other Arab countries. Independent school teachers enter the classroom with a wide range of education backgrounds, many unqualified. According to the Supreme Education Council (2011), more than 30 percent of teachers in Qatar are not qualified to teach, and 31 percent of teachers in Qatar have no formal qualifications to teach, 35 percent of whom are teaching in Independent schools. Although Qatar hopes to achieve 70 percent Qatarization of teachers and staff in these schools in the near future (Supreme Education Council, 2011), only 25 percent of teachers in Independent schools are Qataris.

There is also a great diversity among the parents who send their children to Independent schools. Qatar has a large expatriate population-in 2010, 79.7 percent of all residents were foreign citizens (Sambidge, 2010)_and many expatriate families enroll their children in Independent schools. Parents include Qatari citizens, while expatriates are mostly Arab nationals such as Syrians, Yemenis, Jordanians, Sudaneses and Palestinians. Regarding parents' view of Independent schools, the Social \& Economic Survey Research Institute (2011) reports that only 49 percent of parents with a child at an Independent school would keep the child at the same school type, and only 39 percent of parents who sent the child to Independent schools reported "very satisfied" on the survey.

\footnotetext{
1 A cohort is simply the group of Independent schools that opened in that particular year. For example, cohort 1 contained 12 schools that opened in 2004. Cohort 2 schools opened in 2005 and cohort 3 in 2006. There are currently 8 cohorts in the Independent school system in Qatar.
} 


\section{Methods}

This paper examines teachers', school leaders', and parents' perceptions of the impact of the Independent school model on teaching and learning in the Qatari education context. More specifically, it explores the possible education issues that have surfaced during this fastpaced education reform and seeks to gain insight into the stakeholders' perspectives regarding how far this charter-like movement is applicable to the Qatari teaching situation. This qualitative research study provides understanding how stakeholders interpret their reality by identifying and describing their perceptions of Education for a New Era. For this purpose, an open-ended questionnaire was used to establish the effects, impact, challenges, advantages, and disadvantages of EFNE from principals', teachers', and parents' viewpoints. The research objectives are as follows:

1. What are the effects of EFNE on principals, teachers, parents, and students?

2. What is the impact of EFNE on principals, teachers, parents, and students?

3. What are the challenges that these stakeholders face as a result of the reform?

4. What are the advantages and disadvantages of the Qatari school reform as perceived by principals, teachers, and parents?

\section{Research Design}

Three questionnaires were designed to examine respondents' experiences with EFNE and elicit information from each group of stakeholders regarding the effects of EFNE in their particular context, the challenges they face, and the advantages and disadvantages of the reform. The instruments were initially written in English, then translated into Arabic and judged for the quality of the translations by bilingual native Arabic speakers. Face validity was obtained by having two bilingual professors who are well qualified in conducting research examine each questionnaire and determine if the questionnaire in the Arabic translation was accurately asking participants to ex- plain the effects, impacts, advantages and disadvantages, and challenges of the education reform in Qatar.

Regarding the exploratory nature of the study that seeks to investigate the stakeholders' perceptions, open-ended questions were more appropriate for the purposes of this research. While closed questions allow researchers to collect data that can be analyzed statistically and yield generalizable results, the narrative comments from open-ended questions provide a forum for explanations, meanings, and new ideas that allow us to describe a phenomenon as lived and perceived by the respondent (Cohen, Manion, \& Morrison, 2007).

Initially, all 12 cohort 1 Independent schools were asked to participate in this study because these schools have the longest tenure in the Independent school system. However, only 6 of the 12 schools agreed to participate. The questionnaires were delivered to the principals of these schools accompanied by a letter describing the purpose of the study and explaining that confidentiality and anonymity would be maintained. Principals were requested to fill out their questionnaires and ask the teachers to fill out their own questionnaires. Principals were also requested to randomly provide teachers with parent surveys for students to take home and then return to teachers.

One principal, 40 teacher, and 100 parent questionnaires were delivered to each school, and participants were told when the questionnaires would be retrieved. Completed questionnaires were collected and translated from Arabic to English. The bilingual researcher adjusted the language to improve readability but did not alter the content or meaning. The sample included six schools: 6 principals (100 percent return rate), 121 teachers (51 percent return rate), and 142 parents (24 percent return rate).

\section{Data Analysis}

The responses were grouped according to each survey question. Responses to each open-end- 
ed question were examined in the context of the research questions. During the analysis, several themes emerged. Themes were then content analyzed and relevant quotes were integrated into various themes in order to support or refute particular findings. The rationale was to provide an accurate account of the stakeholders' perceptions of the reformed education system known as Education for a New Era.

\section{Limitations}

As with any study, there are limitations that must be considered. Survey research only provides respondents' verbal descriptions of their perceptions of EFNE. Participant responses cannot always be taken as totally accurate descriptions of what the respondents actually do or really think. In addition, open-ended questionnaires often represent an over simplification of social reality. Nevertheless, this research provides a snapshot of the stakeholders' perceptions. Finally, anytime translation is involved in research, there is always a concern regarding what may or may not be lost in the translation or how translated questionnaires may shape respondents' responses. In spite of these limitations, this research provides valuable insights into principals', teachers', and parents' perceptions of the education reform EFNE, its effects, advantages, disadvantages, and the challenges they experience.

\section{Findings}

The results of the study are presented in three major sections, each elaborating on a single group of stakeholders' perceptions. First, the principals' perceptions are introduced, followed by the teachers', and then the parents' perceptions. Each section focuses on the major themes that emerged from analysis of the responses of one group of stakeholders.

\section{Principals' Perceptions}

The principals' questionnaire asked whether the reform led to changes in their leadership style and roles as school leaders; their perceived impact of the reform on teachers, students, and the school as a whole; and the challenges that they and their schools face in the implementation of EFNE. The analysis of responses shows that EFNE has had positive effects on the principals' leadership styles and on teachers. Nevertheless, it also challenges both groups in some ways.

\section{What are the Effects and Impact of EFNE on Principals?}

According to the data collected from school principals, the reform has led to a change in their leadership style in several ways. When asked whether the reform has impacted their relationship with teachers and staff, principals indicated they needed to change their leadership by departing from the old authoritarian style, as indicated in the following comment: "Yes, there was a change of leadership interpretation, from its earlier meaning of taking traditional and authoritarian decisions." Another change in leadership style was pointed out-namely, a shift from an authoritarian to a more democratic style. With the introduction of EFNE, principals are using teamwork and involving their staff in the decision-making process. One of the respondents wrote, "Yes, the idea and the application of the principle of subsidiarity, taking the views of the teams working with me." Another principal added that the reform has even changed his perception of his role, where he now sees himself as a "mentor and motivator."

Four out of the six respondents mentioned that new roles have been added to their initial role as school manager. Principals are now responsible for the effectiveness of their staff, forcing principals to organize and provide professional development for teachers and staff in order to implement the reform. One participant commented, "Yes, we have examined the impact on the experiences of other countries; this increases the number of workshops related to specialization and leadership."

While all the surveyed principals admitted that EFNE led to an improvement in their 
leadership style, they were divided in their perception of the impact of the reform on their relationship with parents. Some of the respondents indicated that as a result of the reform, they now endure increased pressure from parents. The reform created strong competition among schools because parents are free to choose schools that are most suitable to their children's needs and profiles. Therefore, school leaders have to deal with parents who become very demanding and tend to blame the principal for every mistake. One of the principal's response summarizes this thought: "Parents have become more aggressive with the leadership, blaming principals for all mistakes." Other respondents think that the reform had a positive impact on their relationship with parents. It created more opportunities for communication with parents and allowed for involving them in school activities.

The last theme relating to the principals' perceived impact of the reform is increased accountability. In spite of the high workload incurred by the introduction of the reform, respondents declare that there is an increase in teachers' commitment to their job. Many spend more time at school and work harder to improve their students' performance.

\section{What are the Challenges Principals Face as a Result of the Reform?}

Analysis of the principals' responses about the challenges that they and their schools face revealed one major challenge, namely, the unrealistic requirements of the SEC that places increased pressure on the schools and the teachers. There is "continuous adaptation and change of policies made at the level of the SEC." This creates confusion and makes it difficult for schools to cope with and implement policy changes. One of the principals pointed out that the main challenge that his school faces is the "confusion in the offices of the Supreme Education Council and the lack of clarity in planning."

In addition to the pressure endured by the schools, there is also pressure on teachers. For instance, teachers are required to complete additional tasks to those they used to perform when they worked at Ministry of Education schools (MOES), such as selecting appropriate instructional approaches, selecting or developing materials, and assessing students' needs. These new roles have been added to a traditional schedule that does not allow for the additional time they require.

Finally, principals themselves are challenged by the frequent changes in policies and procedures and the top-down nature of the decision-making process at the SEC. This point was succinctly described by one of the respondents who wrote that there is "control from the Supreme Education Council for everything in schools, and my job is to obey the orders." According to this individual, there is an increase in the bureaucracy because of EFNE, and this has a perceived impact on the principal's role. In addition, the bureaucracy takes the form of micromanaging that has greatly changed what principals do.

\section{Teachers' Perceptions}

Teachers' perceptions of the reform are based on responses to the questions that ask about the effect of the reform on them as well as on their students, the challenges they face, and their perceived advantages and disadvantages of EFNE. This section elaborates on the results of the analysis of these major questions.

\section{What Are the Effects and Impact of EFNE on Teachers?}

When asked about the effects of the reform, most teachers (98 percent) declared that it has led to major changes in their instructional practices. One teacher wrote, "It opens horizons for me to teach differently." While a former teacher in Ministry of Education schools wrote that the reform "has led to a giant leap in education in Qatar. It has affected many aspects of my teaching, a better teaching environment, more quality-oriented teaching, more IT support, a wider variety of resources, greater opportunities for professional devel- 
opment; this should undoubtedly result in better teaching practices."

Teachers declared that the reform has improved the profession. It encourages teachers to "become more innovative" and "creative." It also provides them with ample opportunities to "develop professionally, thanks to the workshops it offers to teachers," and to "look for modern teaching methods of teaching and learning." Teachers also indicated that the reform resulted in significant improvement in their instructional practices. Roughly 90 percent of teachers indicated that, with the reform, they are now using "modern teaching and learning strategies and methods." About 66 percent of the respondents claim that, as a result of the reform, their classes have become more student centered. One teacher wrote:

Yes, it [the reform] improved my teaching and lesson preparation skills. It changed my teaching style from one where the student's role was minor, no more than 10 percent, and the role of the teacher was major, more than 90 percent, to one where the role of the teacher does not exceed 10 percent and 90 percent is the student role.

Other teachers pointed out: "I am now using different activities that engage students and help them to be active and enhance their learning." And, "Yes, the reform changed my style of teaching to a student-centered education." From these comments, teachers seem to incorporate techniques that make their classes more student centered. The learner is now the focus of the learning process. Teachers claim to use activities that engage students, foster student cooperation, and shift attention from a focus on the teacher to emphasize the role of the learner who becomes an active participant in the learning process.

Another important change in the teachers' practices is the use of technology. More than 70 percent of the respondents point out that the reform has improved their use of technology in lesson preparation, actual teaching, and test administration. They integrate various educational technology tools, like the interactive board, the web, and computers. The following participants' comments show these changes:

Yes, it [the reform] affected me. I start using new sources in my teaching. For example, I use technology when I prepare lessons, taking into account individual differences among students.

I start using technology in my teaching and in my preparing for the daily lesson plan and in preparing the worksheets for my students, taking into account individual differences.

I now use technology in teaching, like giving exams and homework through the web (online homework).

The above responses not only point to the teacher's integration of technology in their daily practices, but they also introduce another change in the teachers' practices, namely, the incorporation of differentiated instruction in teaching. Teachers declare that the reform has helped them to "pay attention to multiple intelligences" and "consider different student learning styles" when planning and teaching.

While most teachers hold the view that the reform has positively changed their classroom performance, they were divided in their perception of the impact of the reform on the students. Roughly 60 percent of the teachers think that the reform has improved the students' class performance and achievement. It "increases their ability to rapidly understand and comprehend content" and provides them with the opportunity to become "more active and interested in learning." With the reform, students have developed new skills, like the use of technology, research, critical thinking, problem solving, and the English language. As a result, they have become more "self-reliant and independent," where they rely less on the teacher and "do their work by themselves." In brief, it "improved the students' academic level."

However, more than 40 percent of the respondents declared that the reform has caused students to develop a negative attitude toward 
learning: they "neglect homework," "lack seriousness in study and depend on private lessons," and they have become more "reckless" and "less willing to study and learn." According to some respondents, the reform had a negative impact on students because it "increased the chaos and lack of compliance with the laws," "increased the burden on students because standards are too high for them," and because "the educational process focuses on quantity not quality."

In summary, the reform helped to increase teacher willingness to develop professionally, to change their teaching styles, and adopt modern instructional strategies and techniques. This is due to the professional development that accompanied the reform, and that helped teachers become aware of and able to incorporate new teaching techniques in classroom practices. It also helped some students benefit and improve academically while failing to engage others in the learning process.

\section{What are the Challenges Teachers Face as a Result of the Reform?}

When asked about challenges, 89 percent of the respondents mentioned several types that revolve around the following major themes: burden on teachers, student misbehavior, and resistance to and ambiguity of the reform.

The major challenge faced by teachers is the increased workload. One of the respondents stated that the "reform implementation is a burden and a time-consuming process." Others mentioned that the reform requires them to complete many additional tasks, such as administrative tasks, yearly and weekly planning, selecting instructional materials, and preparing worksheets. Added to these teaching tasks, the SEC also requires them to prepare a portfolio to apply for licensure, attend "too many workshops," and keep up with the continuous changes added to the reform policy. The extra workload has some negative effects on the teachers' feelings about their work. Some admitted that they are required to do tasks, such as selecting appropriate teaching materials and classroom activities but have not been well prepared to fulfill them. These challenges have resulted in "pressure on the teachers" to keep up with the additional nonteaching tasks, which distracts attention from their teaching. Some teachers wrote that challenges include an "increase in the burden on the teacher, which led [them] to neglect preparation and focus more on the administrative and secretarial work." And others said that "finding sufficient time to meet all the requirements of reform, under the pressure of teaching and other things on the teacher," was also challenging. The following quote also illustrates these thoughts:

The teaching is being the weakest job in the sense the teacher is the person who takes all the blames and responsibilities. The teacher is scared, even though he is sacrificing everything. Instead of getting some appreciation, he gets more loads of work and more pressure.

The second most frequently occurring challenge is student "bad behavior," which was mentioned by 64 percent of the respondents. Students lack motivation and interest in studying, do not do homework, "lack seriousness about studying," and even "lack respect to the teacher." This attitude is partly due to the "no failure" policy, as indicated in the following responses: "The student lack of interest in studying, because they know that success is imperative even without studying," and "the challenges faced by the teacher are the students do not listen to the teacher, neglect the homework, lack respect for the teacher."

Related to this concern about student misbehavior is the complaint from some other teachers (45 percent) that there is a resistance to the reform on the part of students and parents. They argue that "some students do not respond to the reform," and that "the main challenge is encouraging the students and parents to accept the changes of the reform."

Teachers explain that some parents are not only challenged by the amount of their children's homework but also by their limited 
mastery of the English language, which makes it hard to follow up on their kids' education.

\section{What are the Advantages and Disad- vantages of the Qatari School Reform as Perceived by Teachers?}

When asked about the advantages and disadvantages of the reform, more than 60 percent of the teachers declared it had benefits, while 40 percent mentioned a number of limitations.

\section{Advantages of EFNE}

Analysis of teachers' responses point to several perceived advantages of the reform that revolve around the theme of improvement of instructional practices and the education system that, in turn, has benefits for the Qatari society and country. More than 75 percent of teachers pointed out that the reform resulted in the use of modern instructional strategies and techniques that are informed by research and that, they believe, are more useful than the traditional methods that were used before the introduction of EFNE. Other teachers (56 percent) pointed to the freedom to use different teaching strategies and techniques, creating variety in the classroom and making the learning process more enjoyable to both teachers and students. Forty-three percent of the respondents also think that the reform has strengthened English language proficiency because content courses (math and science) are now taught in English.

More specific advantages for the students were spelled out by 64 percent of the respondents who said the reform has helped to change the profile of some learners. They stated "develops student critical thinking and creativity," "helps them to become faster learners," and "increases student independence and autonomy both inside and outside the classroom." Teachers pointed out that "thanks to the curricular changes, the reform helped to raise the level of student progress," and that the "academic levels of students have improved a lot, raising the education level of students. In this competitive world of today, students should have good knowledge (which is provided in the reform)."

Finally 33 percent of the teachers hold the view that the reform contributes to the progress of the country. Some teachers think that the reform helps to improve the education system, and, therefore, helps Qatar to "keep up with international developments around the world" and leads to "progress and development to keep pace with international countries." Also, the reform "illuminates the minds" and "has reformed the whole society." Some of the respondents' quotes illustrate this point: "Finding a generation capable of carrying the burden on the future and build the country." "Yes, it develops both teachers' and students' mentality, and that makes them produce new things and new thoughts to help in the development of the society and the country." These respondents seem to be convinced that the reform is helping to achieve one of its major goals, namely, to establish an effective education system that will create change in society, which, in turn, will help to achieve the vision of Qatar for 2030.

\section{Disadvantages of EFNE}

About half of the teachers (42 percent) declared that the reform does not have any disadvantages. The disadvantages named by the remaining 58 percent of the respondents revolve around the themes of burden on teachers, the fast pace of the reform, its over ambitious nature, and threats to the local culture and language.

The most frequently mentioned disadvantage is the additional work required from teachers. More than 85 percent of the respondents argued that the reform "increased the burden on the teacher," and that, with its advent, "most of the work lies on the teachers' shoulders." Because they are not provided with textbooks and instructional materials, it is not only a time-consuming but also a challenging task to select instructional materials that are appropriate for their teaching situation and their students. In addition, some respondents complained that they have long 
school days, which include many administrative tasks in addition to the numerous professional development workshops that they are required to attend. One of the respondents sums up these disadvantages and describes their effect on the teachers by saying, "Yes, the reform has disadvantages, like the disintegration of the family, because of the burdens of their [teachers] job, the school homework, the administrative work, professional development and the long school day." Other teachers argued that they are exceedingly held responsible for students' success or failure. This attitude is clear from the school as well as the parents, as illustrated in the following response: "The reform is casting the burden on the teacher. But, we should ... make the student feel that he is responsible for the level of achievement. This is important, in my opinion."

The second disadvantage that was highlighted by more than half of the teachers is that the reform has been introduced too hastily. For instance, one teacher declared that the "development in education needs more time and effort." Another observed that there has not been careful consideration of the feasibility of the reform prior to its implementation: "Yes, the reform has disadvantages, because the reform is just theories that may fail or succeed, but we shouldn't adopt all the theories before testing their feasibility and suitability for us." There were 33 percent of the teachers who indicated that "the changes are a lot" and teachers "cannot follow them up." Finally, one respondent recommended that "the reform should be brought about more gradually," which supported other teachers' opinions.

Finally, 46 percent of the respondents pointed to the over ambitious nature of the reform when they wrote that "the main disadvantage is that the curriculum chosen does not suit the educational level of students" because there is a huge amount of information offered for them to study." These comments point out that the curriculum standards are too high, which shifted the focus from helping students to" understand and take advantage of the educational materials" to "cover[ing] all the stan- dards superficially." One possible explanation for these teachers' concerns might lie in one teacher's argument that "the conflict at the top of the pyramid results in the chaos at the bottom. Various companies compete for the profits, but the teacher is the lab for the experience." The foreign education corporations that have developed the reform do not seem to be aware of the specificities of the Qatari context and the readiness of the stakeholders to implement the reform as intended by its designers.

To sum up the teachers' perspective on the reform, it has helped practitioners to improve their daily instructional practices. These responses also indicate that the reform itself and what these teachers have learned and experienced from the reform has greatly shaped their view of teaching, students, and the classroom.

\section{Parents' Perceptions}

\section{What are the Effects and Impact of EFNE on and Students?}

Parents were divided in their opinions about how the reform affected them and their children. About half of the parents surveyed (48 percent) thought that the reform had a positive effect on both parties, while 37 percent thought that it affected them negatively. The remaining 15 percent of parents argued that they saw no changes as a result of EFNE.

One positive effect of EFNE is that it has changed the parents' and children's attitude to education. Thirty-two percent of parents pointed out that their child and they developed a more serious view toward education. Parents wrote, "Children are paying more attention to education and they are learning more in the school," "[EFNE has] a positive impact because my son loves to study now. . . . He became more attracted to the process of education," and "Yes, the impact of reform is clear. I follow-up with my son and I try to answer the questions he asks, which shows his interest in studying, and this affects the child's behavior." Other parents (29 percent) men- 
tioned that the reform increased their children's interest in studying, but they tend to believe that the reason behind this motivation is the fear of failure. One parent wrote, "I notice their [his children] interest in studying and the fear of failing and repeating the year," and another affirmed that "Yes, the reform increased the sense of fear about the education level of our child, and this makes us work harder with him."

However, for 25 percent of the respondents, the reform led to additional pressure and increased the amount of work that parents and children do at home.

I do not feel that there is any improvement in the educational process, but there is pressure on the child and the parents at home because they have to explain the lessons for their child again when they help him with his homework.

Another frequently mentioned reason for the negative attitude to EFNE is the use of English as a medium of instruction (in math and science classes). Due to low proficiency in English, parents are not able to follow up on their children's progress or to provide them with the support they need at home.

Yes, the reform affected me. I cannot understand the new curriculum because it is in English and I do not understand English, and this affected my son. Certainly they must provide courses to teach the English language to the parents.

Parents who argue that they do not see any impact of the reform reasoned that they either see no changes or improvements taking place as a result of EFNE or they contend that the reform did not result in any improvements. To use the words of one respondent, "I cannot see any reform, but instead I see weakness in the academic level." Still others hold the view that the "Independent school system" is a failure.
What are the Challenges Parents Face as a Result of the Reform?

Too much homework. With regard to the challenges faced by parents, 40 percent of the respondents stated that EFNE has influenced them as parents and their children through the amount of homework now required of their kids. They indicated that since the introduction of the reform, the amount of time that parents must spend helping their children complete the work has increased considerably. Parents listed as a disadvantage not only the amount of homework but also the increased dependency of children on parents for help with their studies.

The homework of my son is making me tired, particularly because of the huge amount of homework.

There is an increase of the burden of studying and homework on the student.

As these responses indicate, students have had much more homework since EFNE began, and this has implications for not only the student but also the parents. The following section points out the impact of increased homework.

"I Can't Tutor my Child." Another aspect related to the issue of abundant homework is the added pressure and the difficulty parents face working with their children to complete the daily assigned homework for two reasons. The first reason is that English is used as a medium of instruction in content classes and many parents are not proficient in English, as illustrated in the following quote: "[The reform] affected me negatively because they teach science and math in English and English is a very difficult language. ... My son became more dependent on me in terms of the homework . . Teaching some subjects in English makes it very difficult at home with my child." The second reason is the high standards compared to students' level, as shown in this response: "Standards that are currently taught to 
students are very high, and students can't study his courses without a tutor."

One parent wrote, "Parents must provide a tutor for their son, especially if he is weak in English, and this costs too much money." Findings indicate that 25 percent of the parents wrote that they hired a tutor to help their child for two reasons. The first reason is that English is used as the medium of instruction and English is a barrier for some parents in helping their children succeed academically. The second reason is that the curriculum is too difficult and many parents do not seem to understand it. These reasons, combined with the perceived large amount of and challenging homework, add to the parents' frustration and cause an economic issue because of the need to seek tutoring for their children. This finding is supported by the results of The Social \& Economic Survey Research Institute (2011) which reports that 41 percent of parents with children in primary Independent schools report using a private tutor, and this percentage increases to 56 percent if the child is in secondary school.

A Threat to Arab Culture and Language. Another disadvantage of the reform as perceived by parents is that the innovation constitutes a threat to the Arab culture and language. This concern is due to the use of English as a medium of instruction in math and science classes, in addition to the reduction of time devoted to the study of Arabic and Islamic studies (compared to the time assigned to these subjects prior to the reform). One of the respondents wrote, "There is weakness of the Arabic language and Islamic history," while another stressed, "There is too much focus on the English language, and this weakens Islamic studies and the Arabic language," and a third sarcastically wrote, "Are we going to change our language to the English language?"

The parents believe that students are not getting enough instruction in Arabic language and culture and Islamic studies. They also believe that studying the Quran is becoming a secondary issue, and not as "an integral part of education" as they would like. One parent expressed the concern that the school is teaching neither English nor Arabic well. She wrote that "this reform ruined the boy; he does not know Arabic or English!"

Nevertheless it is worth noting that 4 percent of parents expressed an opposite opinion regarding the perceived weakness of Arab culture and language. For example, one parent described her child's experience in the Independent school with these comments, "There is an increase in religious awareness, particularly the preservation of prayer," and "He is greatly influenced in Islamic Ethics." There were few parents who expressed this perspective and this illustrates the importance of considering the particular school context, as we know that, while schools are held accountable to teach curriculum standards, they differ, to some degree, in climate vision and what is actually taught.

\section{What are the Advantages and Disad- vantages of the Qatari School Reform as Perceived by Parents?}

When asked how EFNE has affected and created challenges for both themselves and their children, the majority of parents indicated that the education reform had both advantages and disadvantages for both parties. We address the advantages in the following section.

\section{Advantages of EFNE}

Another stated advantage of the reform is an improvement in instructional methods. It was clear to 23 percent of parents that the reform" is improving some of the schools' curricula" and "teaching methods" with the introduction of best practices in the classroom. One of the parents explicitly stated that "methods of teaching are better, leading to improved learning . . . and diversity of ideas." While these responses point to the parents' awareness of a general improvement at the level of instructional methodology and approach in general, other responses highlighted more specific progress. Parents seem to recognize some posi- 
tive effects of the reform that center on better pedagogy, improved student assessment and curriculum, and differentiated instruction. Nevertheless, they still believe that the reform has some limitations.

\section{Disadvantages of EFNE}

The disadvantages of EFNE from the parents' perspective centered on teaching and teachers. Parents listed teacher qualifications (35 percent), teacher mobility (2l percent) and the lack of Qatari teachers (8 percent) as some of the problems with EFNE.

Parents thought that the reform led to the loss of good teachers. "The instability of teachers," or rather, "the high mobility of teachers (who change schools too frequently and even leave the country)" seems to be one of the reasons parents are discontent with the reform. Another perceived disadvantage of EFNE is "the low level of some teachers" and the "lack of qualified teachers." One of the reasons, perceived by some respondents, is that Qatari teachers had left the profession and had been replaced by foreign teachers, but these newly recruited teachers, to use one respondent's words, "do not care about their students."

Recent statistics support the accuracy of these few parents in their perception of the current teaching force. As previously mentioned above and worth repeating, only 25 percent of teachers in Independent schools are Qataris; more than 30 percent of school teachers in Qatar are not qualified to teach; and 31 percent of teachers in Qatar have no formal qualifications to teach, 35 percent of whom are teaching in Independent schools.

\section{Discussion}

These findings raise some important issues regarding Qatar's education reform. There are some positive aspects of the reform reported by principals, teachers, and parents. Principals are adapting their leadership style to various situations that arise. Teachers are using innovative teaching strategies and integrating tech- nology in their teaching, and parents state that their children are more serious about education and their English skills are improving. While the majority of participants did not always represent these aspects of Education for a New Era, these are positive issues that need to be further researched and discussed. Nevertheless, the findings point to a positive attitude to the reform that is one of the key factors to change implementation.

These findings also raise concerns that need serious consideration. First and foremost is the large amount of extra work and effort incurred by ENFE. This concern was expressed by all stakeholders and should be considered in the revision of the reform. The extra work and effort could be the reason some stakeholders feel frustration with the reform and the cause of their resistance to it. The high turnover of teachers might be evidence of this concern. Education reform takes time, and although reform can be very ambitious, change should be introduced slowly and gradually. Furthermore, reform planning should take into account the reality of the context so it is not rejected by its implementers and other parties involved in it.

In addition, there is parental concern of the perceived threat toward the Arabic language, culture, and religion. Although in this study parents were the ones to indicate this concern, from our experiences working with school leaders and teachers, the issue of the loss of Arabic identity is not highlighted by parents only. It is often raised when talking with all educators and stakeholders about EFNE. The idea of losing Arabic identity is not limited to education reform, but this concern surfaces within issues such as language-planning policies and immigration planning and policies; the recent awarding of the 2022 World Cup; and in the daily lives of Qataris because of the influx of new knowledge and organizations. Nevertheless, we would argue that some aspects of education reforms are not limited to cultural boundaries but span across all cultures. For example, most reforms will suffer from additional bureaucracy from the governing bodies; curriculum that is not aligned with 
adopted standards; and an initial increase in principals', teachers', and even parents' work as they adapt to the required changes of education reform.

Last, but not least, is the challenge of the continuous reform changes that seems to cause discontent and might lead to lack of consistency in the implementation of the reform. These changes are often introduced in an attempt to improve the reform and make it a better fit for the local context. For instance, with the launch of the reform, schools were free to select instructional materials, and teachers had much maneuvering space in choosing materials that they believe help their learners to reach the curriculum standards. However, now, many schools are required to select one textbook from a list provided by the Supreme Education Council.

Another change is that it seems there is a move away from the initial model of Independent schools that was introduced with EFNE, a decentralized model that provides freedom to schools to select their visions and means to reach standards. In practice, the system is becoming more centralized and schools must follow changes from upper spheres of decision makers, of whom there seem to be too many. This might mean that the model of the decentralized Independent schools may not be appropriate to a context where a centralized model was used and schools were following prescriptions and instructions dictated by the Ministry of Education. The extent to which the model is suitable is also subject to reconsideration because teachers and leaders are challenged by the amount of work in the implementation of the reform.

Steiner-Khamsi argues that a history of skepticism has led to numerous warnings being issued regarding the transferring, borrowing, and lending of education policies and programs. Whether the education transfer is whole, selective, or eclectic, the transfer isolates "education from its political, economic, and cultural context" (Steiner-Khamsi, 2004, p. 201).

Rather than relying on expertise and models designed by and for Western countries, countries like Qatar may consider building up their own expert contingents and encourage local expertise and educators with better knowledge of and experience in the local context to develop and evaluate reform that takes into account the political, economic, social, and cultural factors. These countries should devise reform models that meet their learners' needs and that are appropriate to administrators, teachers, and the local community.

\section{Conclusion}

There are several lessons learned from this study. The first lesson is that it is vital to keep in mind that these findings are context based. In other words, the way principals, teachers, and parents experience the education reform greatly depends on the particular school. Stakeholders' perceptions can vary greatly from one school to another. Nevertheless, Education for a New Era has provided several education improvements that are evident in the principals', teachers', and parents' perceptions reported in this study. These include different leadership styles, the use of different teaching strategies, and great improvement of the English language, to name a few.

Second, although the reform is perceived to have positive effects, it is a daunting process. All stakeholders seem to be struggling to meet the requirements of the reform. The reform is difficult, placing pressure on the teachers, school leaders, and parents and requires them to do tasks that they are not ready to fulfill or do not have the skill to prove successful. To deal with these challenges, all stakeholders require strong commitment and perseverance.

Furthermore, when teachers use education jargon to describe their teaching, we can only assume that this occurs in their classroom. Thus, follow-up interviews would provide a richer description of stakeholders' perceptions. In addition, comparing these results to the other Independent school cohorts would provide valuable insights. Teachers' claims about the changes that the reform has brought up at the level of their classroom practices might not mean that these changes are actually being 
implemented in actual practice. Research is needed to explore the extent to which teachers claims conform to what they actually do in practice.

Finally, underlying successful education reform takes patience and the courage to approach the process of education in very different ways, taking into consideration the insights from stakeholders. In light of these findings, it would be wise for the architects of the reform and those in charge of its implementation to examine the perceptions of the issues that have emerged in this study and consider the role all stakeholders have in education reform in Qatar.

\section{References}

Adams, P., \& O'Neill, J. (2010). Heeding parents in educational reform. New Zealand Journal of Teachers' Work, 7(1), 1-2.

Bailey, B. (2000). The impact of mandated change on teachers. In N. Bascia \& A. Hargreaves (Eds.), The sharp edge of educational change: Teaching, leading, and the realities of reform (pp. 112-128). New York. RoutledgeFalmer.

Brewer, D., Augustine, C., Zellman, G., Ryan, G., Goldman, C., Stasz, C., \& Constant, L. (2007). Education for a new era design and implementation of K-12 education reform in Qatar. Rand Qatar Policy Institute, Santa Monica CA: Rand Corporation.

Carless, D. R. (2001). A case study of curriculum implementation in Hong Kong. In D. R. Hall \& A. Hewings (Eds.), Innovation in English language teaching: A reader (pp. 263-274). London: Routledge, in association with Macquarie University, Macquarie Park, NSW, AU, and The Open University, Milton Keynes, UK.

Christenson, S. L., \& Anderson, A. R. (2002). Commentary: The centrality of the learning context for students' academic enabler skills. School Psychology Review, 31, 378-393.

Cohen, L., Manion, L., \& Morrison, K. (2007). Research Methods in Education (6th ed.). Oxford: Routledge.
Darling-Hammond, L. (1997). The right to learn: A blueprint for creating schools that work. San Francisco: Jossey-Bass.

Fullan, M. (2001). The new meaning of educational change (3rd ed.). New York: Teachers College Press.

Fullan, M. (2011, May). Choosing the wrong drivers for whole system reform. (Seminar Series Paper No. 204). Melbourne, AU: Centre for Strategic Education.

Fullan, M. G., \& Miles, M. B. (1992). Getting reform right: What works and what doesn't. Phi Delta Kappan, 73(10), 745-749.

Hargreaves, A., Earl, L., Moore, S., \& Manning, S. (2001). Learning to change: Teaching beyond subjects and standards. San Francisco: JosseyBass.

Hargreaves, A., \& Fullan, M. (1998). What's worth fighting for out there? New York: Teachers College Press.

Hargreaves, A., \& Goodson, I. F. (1996). Teachers' Professional Lives. New York: Routledge.

Henderson, A. T., \& Mapp, K. L. (2002). A new wave of evidence: The impact of school, family, and community connections on student achievement. Austin, TX: Southwest Educational Development Laboratory.

Horn, R. (2002). Understanding educational reform: A reference handbook. Santa Barbara, CA: ABC-Clio.

Houston, P. D. (1998, June 3). The ABCs of administrative shortages. Education Week, 17(38), pp. 32, 44 ..

Lewis, A. C., \& Henderson, A. T. (1997). Urgent message: Families crucial to school reform. Washington, DC: Center for Law and Education.

Kilgallon, P., Maloney, C., \& Lock, G. (2008). Early childhood teachers coping with educational change. Australian Journal of Early Childhood, 33(1), 23-29.

Kirk, D. J., \& Jones, T. C. (2004). Effective schools. Dallas, TX: Pearson Education. Retrieved from pearsoneducation.com

Kirk. D., \& Macdonald, D. (2001). Teacher voice and ownership of curriculum change. Curriculum Studies. 33(5), 551-567. 
Lamie, J. M. (2005). Evaluating changes in English language teaching. London: Palgrave Macmillan.

Leithwood, K., Louis, K. S., Anderson, S., \& Wahlstrom, K. (2004). Review of research: How leadership influences student learning. New York: The Wallace Foundation.

Lieberman, A. (1997). Navigating the four Cs: Building a bridge over troubled waters. In D. J. Flinders \& S. J. Thornton (Eds.). The curriculum studies reader (pp. 350-354). New York: Routledge

Lieberman, A., \& Pointer-Mace, D. H. (2008). Teacher learning: The key to educational reform. Journal of Teacher Education, 59(3), 226-234.

Lewis, A. C., \& Henderson, A. T. (1997). Urgent message: Families crucial to school reform . Washington, DC: Center for Law and Education.

Margolis, J., \& Nagel, L. (2006, Fall). Education reform and the role of administrators in mediating teacher stress. Teacher Education Quarterly, 33(4), 143-159. Retrieved from teqjournal.org/Back\%20Issues/Volume $\% 2033 / \mathrm{V} O \mathrm{~L} 33 \% 20 \mathrm{P}$ D F S / 33_4/21margolis\&nagel-33_4.pdf

Markee, N. (1997). Managing curricular innovation. Cambridge, UK: Cambridge University Press.

Matthews, L. J., \& Crow, G. M. (2003) Being and becoming a principal: Role concepts for contemporary principals and assistant principals. Boston: Allyn and Bacon.

Nunan, D. (2003). The impact of English as a global language on educational policies and practices in the Asia-Pacific region. TESOL Quarterly, 37(4), 589-613.

Rea-Dickens, P., \& Germaine, K. P. (Eds.). (1998). Managing evaluation and innovation in language teaching: Building bridges. London: Longman.
Sambidge, A. (2010). Expat workers to drive Qatar population growth. Arabian Business. Retrieved from: www.arabianbusiness.com/ expat-workers-drive-qatar-populationgrowth-304109.html

Sammons, P. (1999) School effectiveness: Coming of age in the 21st century. Lisse, Neth.: Swets and Zeitlinger.

Schweisfurth, M. (2002). Teachers, democratization and educational reform in Russia and South Africa. Providence, RI: Symposium Books.

Social \& Economic Survey Research Institute (2011). Education in Qatar: Parent satisfaction, tutoring demand, school choice and coed schooling (Executive Summary Report). Doha, Qatar: Author.

Spillane, J. P. (1999). External reform initiatives and teachers' efforts to reconstruct their practice: The mediating role of teachers' zones of enactment. Journal of Curriculum Studies, 31(2), 143-175.

Steiner-Khamsi, G. (2004). Blazing a trail for policy theory and practice. In G. SteinerKhamsi (Ed.), The global politics of educational borrowing \& lending (pp. 201-220). New York: Teachers College Press.

Supreme Education Council (2012). Independent Schools. Retrieved from: http://www.sec.gov.qa/En/pages/Glossary.aspx

Supreme Education Council (2011). Above $30 \%$ teachers not qualified. Available from: http:// www.thepeninsulaqatar.com/qatar/163929above-30pc-teachers-not-qualified.html

Supreme Education Council (2008). What U.S. research says about the benefits of parental involvement in children's learning and development from birth through high school. Education For A New Era Magazine. Retrieved from: http://www.english.education. gov.qa/ section/sec/annual 20-21.

Troudi, S., \& Alwan, F. (2010) Teachers' feelings during curriculum change in the United Arab Emirates: Opening Pandora's box. Teacher Development 14(1), 107-121. 